\title{
A study of the possibility of sprites in the atmospheres of other planets
}

\author{
Yoav Yair, ${ }^{1}$ Yukihiro Takahashi, ${ }^{2}$ Roy Yaniv, ${ }^{1,3}$ Ute Ebert, ${ }^{4,5}$ and Yukihiro Goto ${ }^{6}$ \\ Received 28 November 2008; revised 29 March 2009; accepted 4 June 2009; published 4 September 2009.
}

[1] Sprites are a spectacular type of transient luminous events which occur above thunderstorms immediately after lightning. They have shapes of giant jellyfish, carrots, or columns and last tens of milliseconds. In Earth's atmosphere, sprites mostly emit in red and blue wavelengths from excited $\mathrm{N}_{2}$ and $\mathrm{N}_{2}^{+}$and span a vertical range between 50 and $90 \mathrm{~km}$ above the surface. The emission spectra, morphology, and occurrence heights of sprites reflect the properties of the planetary atmosphere they inhabit and are related to the intensity of the initiating parent lightning. This paper presents results of theoretical calculations of the expected occurrence heights of sprites above lightning discharges in the $\mathrm{CO}_{2}$ atmosphere of Venus, the $\mathrm{N}_{2}$ atmosphere of Titan, and the $\mathrm{H}_{2}-\mathrm{He}$ atmosphere of Jupiter. The expected emission features are presented, and the potential of detecting sprites in planetary atmospheres by orbiting spacecraft is discussed.

Citation: Yair, Y., Y. Takahashi, R. Yaniv, U. Ebert, and Y. Goto (2009), A study of the possibility of sprites in the atmospheres of other planets, J. Geophys. Res., 114, E09002, doi:10.1029/2008JE003311.

\section{Background}

\subsection{Observations of Planetary Lightning Activity}

[2] Apart from Earth, lightning has been discovered or inferred in several other planetary atmospheres in the solar system. We shall review these observations briefly, and would like to refer the interested reader to the extensive reviews by Desch et al. [2002], Aplin [2006], and Yair et al. [2008]. On Venus, lightning activity had been deduced on the basis of the VLF emission detected by the Soviet landers Venera 11 and 12 [Ksanfomality, 1980]. However, the data from topside observations by various spacecraft have not shown unequivocal optical or electromagnetic signatures, especially after the flybys of the Galileo and Cassini spacecrafts [Gurnett et al., 1991, 2001]. Krasnopolsky [2006] obtained high-resolution spectra of Venus in the NO band at $5.3 \mu \mathrm{m}$ and found an NO content of $5.5 \pm 1.5 \mathrm{ppb}$ below $60 \mathrm{~km}$ altitude. Such a concentration cannot be explained by cosmic ray induced chemistry and the suggested mechanism is production by lightning. Lately, on the basis of the Venus Express magnetometer data, Russell et al. [2007] showed that lightning activity on Venus is of the same order of magnitude as on Earth, namely $\sim 50 \mathrm{~s}^{-1}$. There is still uncertainty concerning the global Venusian lightning rate in

\footnotetext{
${ }^{1}$ Department of Life and Natural Sciences, Open University of Israel, Ra'anana, Israel.

${ }^{2}$ Department of Geophysics, Tohoku University, Sendai, Japan.

${ }^{3}$ Department of Geophysics and Planetary Sciences, Tel-Aviv University, Tel-Aviv, Israel.

${ }^{4}$ Centrum Wiskunde and Informatica, Amsterdam, Netherlands

${ }^{5}$ Faculty of Physics, Eindhoven University of Technology, Eindhoven, Netherlands.

${ }^{6}$ Department of Electrical Engineering, Tohoku Gakuin University, Tagajo, Japan.

Copyright 2009 by the American Geophysical Union. 0148-0227/09/2008JE003311\$09.00
}

view of the fact that no plausible charge separation mechanism had been suggested to account for such a high flash rate [Levin et al., 1983]. On Mars, there are presently no direct observations of electrical activity, but it is expected that the frequent small dust devils $(\mathrm{z}<100 \mathrm{~m})$ and larger storms $(\mathrm{z} \sim 10 \mathrm{~km})$ would be electrified owing to triboelectric charging processes and display some form of discharge [Melnik and Parrot, 1998; Farrell et al., 1999]. While there were theoretical predictions for lightning activity in the convective methane clouds of Titan [Tokano et al., 2001], none were detected even after 17 closerange flybys by the Cassini spacecraft [Fischer et al., 2007]. This may indicate that thunderstorms are exceptionally rare or even nonexistent in that atmosphere, and attest to the weakness of charge build up processes within the methane clouds. At the giant planets, the Voyager, Galileo, Cassini, and New Horizons missions found clear indications that lightning is prevalent on Jupiter [Borucki and Magalhaes, 1992; Little et al., 1999; Baines et al., 2007] and also occurs on Saturn [Gurnett et al., 2005; Fischer et al., 2007]. They are thought to occur in the deep $\mathrm{H}_{2} \mathrm{O}$ clouds that exist in these atmospheres and are estimated to be $10^{3}$ to $10^{6}$ times more energetic than on Earth [Yair et al., 1998; Gurnett et al., 2005].

\subsection{Transient Luminous Events}

[3] Transient luminous events (TLEs) is the collective name given to a wide variety of optical emissions which occur in the upper atmosphere above active thunderstorms. These very brief (from few to tens of ms), colorful phenomena were discovered serendipitously in 1989 [Franz et al., 1990], and since then have been extensively studied from the ground, aircraft, balloons, the space shuttle, the International Space Station, and from various orbiting satellites. There is now considerable theoretical and observational literature that covers the phenomenology, morphology and relationship to lightning parameters of TLE generation (see for example Williams et al. [2006], the review by Neubert et al. [2008], or the special 
issue of Journal of Physics D Applied Physics, on streamers, sprites, and lightning edited by Ebert and Sentman [2008]). Distinct classes and names (Elves, sprites, carrots, columns, angels, jets, trolls, and pixies) were given to the various shapes of these optical emissions, all of which occur in mesospheric and stratospheric heights above active thunderstorms. Sprites are the most spectacular type of TLE, with shapes reminiscent of giant jellyfish, carrots, or columns and they are usually associated with intense positive cloud-toground lightning $(+\mathrm{CG})$ that posses a large charge moment change [Cummer and Lyons, 2005]. The suggested mechanism for sprite production is the emergence of a quasielectrostatic (QE) field between the cloud top and the ionosphere after the cloud's positive charge center is removed from the thundercloud. This QE field can be sustained for a time of the order of magnitude of the local relaxation time (which depends on the local conductivity), and it is sometimes strong enough to exceed the conventional breakdown field in mesospheric heights [Pasko et al., 1997]. Thus, sprites can be delayed by approximately tens of milliseconds from the parent lightning [São-Sabbas et al., 2003] and they are usually initiated in the height range of $70-80 \mathrm{~km}$, from which they propagate in visible tendrils downward and upward. High-speed imagery [StenbaekNielsen et al., 2007; McHarg et al., 2007] showed that sprites start with downward moving streamer heads which have sizes of the order of hundred meters or less. Sprite brightness can reach several mega Rayleigh [Gerken et al., 2000], lasting up to several tens of milliseconds. The main emissions in sprites include the first positive $\left(\mathrm{N}_{2} 1 \mathrm{P}\right)$ and second positive $\left(\mathrm{N}_{2} 2 \mathrm{P}\right)$ band systems of $\mathrm{N}_{2}$, the $\mathrm{N}_{2}$ LymanBirge-Hopfield ( $\mathrm{LBH}$ ) band system and the first negative band system of $\mathrm{N}_{2}^{+}\left(\mathrm{N}_{2}^{+} 1 \mathrm{~N}\right)$ [Morrill et al., 2002]. The molecular basis for various sprite emissions is reviewed in detail by Pasko [2007] and by Sentman et al. [2008]. Sprites seem to play an important role in mesospheretroposphere coupling that bears on the global electrical circuit [Füllekrug and Rycroft, 2006]. Several observations suggest that certain types of jets that evolve into sprites may connect the top of thunderstorms directly to the ionosphere [Pasko et al., 2002]. The potential role of sprites in altering the chemical properties of the mesosphere was recently reviewed by Gordillo-Vázquez [2008]. There are few reports that sprites were produced by negative cloud-to-ground flashes [Barrington-Leigh et al., 1999] or by Intracloud (IC) discharges [Ohkubo et al., 2005], but these are probably rare exceptions. The inhomogeneity and transient variability of the terrestrial atmosphere at mesospheric heights is believed to play a crucial role in the initiation of TLEs; that is, gravity waves, chemical reactions, and meteor ablation products modify the local electrical properties of the mesosphere, making it more conducive to electrical breakdown processes. Sprites, haloes, and elves seem to be ubiquitous around the planet and were reported over most major centers of lightning activity on Earth. Spacebased observations offer a global vantage point for studying the planetary occurrence rate of TLEs.

\section{Model Description}

[4] Since lightning has been found in other planetary atmospheres, it seems reasonable to assume that some form of TLEs may also occur on those planets. Detailed calculations of the conventional breakdown parameters for various planetary atmospheres have been presented lately by Roussel-Dupré et al. [2008], for a range of external electric fields. Here we present initial calculations of the necessary lightning induced charge moment changes and possible atmospheric heights for the occurrence of sprites on Venus, Mars, Titan, and the gas giant Jupiter. The calculations of the breakdown parameters and the critical electric field $\mathrm{E}_{\mathrm{k}}$ as a function of atmospheric pressure for the atmospheres of several types of solar system objects are based on Sentman [2004]. In that work, detailed Boltzmann modeling of the electron distribution function as a function of the pressurenormalized electric field $[\mathrm{E} / \mathrm{p}]$ was used to calculate $\mathrm{E}_{\mathrm{k}}$ values for various atmospheric compositions, representing the major planets. For simplifying the computation, Sentman [2004] classified planetary atmospheres to four types based on their major constituents (e.g., $\mathrm{N}_{2} / \mathrm{O}_{2}, \mathrm{CO}_{2} / \mathrm{N}_{2}, \mathrm{H}_{2} / \mathrm{He}$, and $\mathrm{N}_{2} / \mathrm{CH}_{4}$ ), corresponding to Earth, Venus/Mars, the giant planets, and Titan/Triton, accordingly. The ionization $(\alpha)$ and attachment $(\eta)$ coefficients and the electron mobility $(\mu)$ were calculated as a function of the reduced electric field over the range $10 \leq \mathrm{E} / \mathrm{p} \leq 100 \mathrm{~V} \mathrm{~cm}^{-1}$ torr $^{-1}$ and $\mathrm{T}=300 \mathrm{~K}$, using the following analytical approximations:

$$
\begin{gathered}
\frac{\alpha}{P}=A_{i} \times \exp \left(\frac{-B_{i}}{E / P}\right) \\
\frac{\eta}{P}=A_{a} \times\left(\frac{E}{P}\right)^{-2} \times \exp \left(\frac{-B_{a}}{E / p}\right)
\end{gathered}
$$

where the coefficients $A_{i}, B_{i}, A_{a}$, and $B_{a}$ were taken from Sentman [2004], P is the ambient pressure, and $\mathrm{E}$ is the electric field strength. The field where the ionization rate just surpasses the attachment rate for given pressure and temperature, is called the conventional breakdown field $\mathrm{E}_{\mathrm{k}}$; it should not be confused with the field required for streamer propagation after emergence which is lower. We calculated the values of $\mathrm{E}_{\mathrm{k}}$ over a wide range of pressures and temperatures in each planet's atmosphere, assuming that sprites occur below the base of the ionosphere and above the uppermost planetary cloud layer. As the determining physical quantity is the reduced field $\mathrm{E} / \mathrm{N}$, where $\mathrm{N}$ is the number density of molecules in the respective atmosphere, we used the ideal gas law to derive the $\mathrm{E} / \mathrm{N}$ values from the $\mathrm{E} / \mathrm{p}$ values at $\mathrm{T}=300 \mathrm{~K}$.

[5] In its simplest form the QE model assumes a thundercloud with a dipole charge structure where positive charge resides above the negative lower one. Since this structure was generated through slow charge separation, the cloud at this stage is electrically neutral and the electric field above it decays rapidly. After the positive charge is removed by a cloud-to-ground flash, the remaining negative charge produces an instantaneous large quasi-electrostatic monopole field. The conducting surface of the Earth immediately screens this electric field; the surface-thundercloud system at the altitude of the mesosphere can then be approximated by a dipole field (see below). As an elementary calculation shows, this field at mesospheric heights and above is characterized by the charge moment change (CMC), i.e., the charge times its height above the surface [Wilson, 1925]. 
In physical terms, the charge moment is the dipole moment of the cloud-Earth system after the lightning stroke; it is the leading term in a multipole expansion [Jackson, 1975].

[6] This field endures for a time equal or shorter to the local electrostatic relaxation time in each altitude given by $\tau_{\sigma}(\mathrm{z})=\varepsilon_{0} / \sigma(\mathrm{z})$, where $\sigma(\mathrm{z})$ is the height-dependent conductivity. For typical mesospheric values, at $70 \mathrm{~km} \sigma(\mathrm{z})=$ $10^{-7} \mathrm{~S} \mathrm{~m}^{-1}$ and $\tau_{\sigma}(\mathrm{z})$ is equal to $10^{-4} \mathrm{~s}$. The transient field accelerates ambient electrons and leads to excitation and ionization, and eventually to the formation of a sprite with its characteristic emissions. A thorough discussion of this approach can be found in the work by Pasko et al. [1997] and Raizer et al. [1998]. In order to compute the expected field above thunderclouds in other planets, we place a charge equivalent to the uppermost charge center expected in each cloud type.

[7] Then the electrostatic field for a charge Q, located at an altitude $Z_{s}$ above the conducting surface at altitude zero is in three-dimensional space $(\mathrm{x}, \mathrm{y}, \mathrm{z})$ :

$$
\begin{aligned}
E_{z}(x, y, z)= & \frac{Q}{4 \pi \varepsilon_{0}} \times\left[\frac{(z-Z s)}{\left[x^{2}+y^{2}+(z-Z s)^{2}\right]^{\frac{3}{2}}}\right. \\
& \left.-\frac{(z+Z s)}{\left[x^{2}+y^{2}+(z+Z s)^{2}\right]^{\frac{3}{2}}}\right]
\end{aligned}
$$

This approximation was given by Raizer et al. [1998]. The first term accounts for the cloud charge while the second accounts for the equipotential earth represented by the image charge trick [Jackson, 1975]. On the axis of the cloud-Earth dipole $(x=y=0)$, and neglecting the contribution of the ionosphere, the vertical component $E_{z}$ at altitudes where $z \gg$ $\mathrm{Z}_{\mathrm{s}}$ reduces to

$$
E_{s}=Q\left[\frac{1}{\left(Z-Z_{s}\right)^{2}}-\frac{1}{\left(Z+Z_{s}\right)^{2}}\right]
$$

Similar expressions were used by Pasko et al. [1997, 1998], Hiraki and Fukunishi, [2006], and many others for terrestrial sprites.

[8] The model represents the charge in the thundercloud by point charges which is a valid approximation at heights much larger than the extension of the charged regions; it does not describe the detailed temporal evolution of the breakdown process and the evolution of sprites as the models of Pasko et al. [1998, 2001]. Rather, we postulate a set of simple charge configurations in various types of clouds on other planets. This approach oversimplifies the complex reality of the charge distribution so as to account for the uncertainties in both charge locations and lightning discharge types in Venus, Titan and the giant planets, however, it takes the leading dipole field into account. The methodology is inspired by Wilson's [1925] reasoning for predicting that field-induced electrical breakdown can occur high in the terrestrial atmosphere $(80 \mathrm{~km})$ : where $\mathrm{E}_{\mathrm{s}}$ equals to or surpasses the critical breakdown field $\mathrm{E}_{\mathrm{k}}$, the atmosphere can produce a discharge (e.g., sprites in present-day terminology) if the right concentration of free electrons is present. The ubiquity of galactic cosmic ray- and solar EUV-induced ionization in the solar system ensures that this condition is likely to be met in all the planets we study. Updated discussions of the various breakdown processes possible under the influence of an external field are found in the work by Cooray [2003] and Treumann et al. [2008]. By definition $\mathrm{E}_{\mathrm{k}}$ is the homogenous electric field in which the ionization rate exceeds the attachment (deionization) rate, such that free electrons can grow into an avalanche and further into a streamer. This value is therefore an upper boundary for the initiation of a conventional breakdown process, but it is well known that if there are field inhomogeneities like in the neighborhood of particles (or laboratory electrodes), the field can exceed $\mathrm{E}_{\mathrm{k}}$ locally and start a discharge while it is below $\mathrm{E}_{\mathrm{k}}$ further away. Once created, a streamer discharge enhances the electric field at its tip [Raether, 1933] and therefore can propagate into regions where the field is well below $\mathrm{E}_{\mathrm{k}}$.

[9] The vertical pressure and temperature profiles needed for calculation of the values of $E_{k}(z)$ were taken from the Planetary Atmospheres Node of the Planetary Data System (PDS) (http://atmos.nmsu.edu/) for Venus, Mars and Titan, and from Stanford's standard atmosphere computations (http://aero.stanford.edu/StdAtm.html) for the case of Earth's atmosphere. Although little is known about the locations and magnitudes of charge centers in the thunderclouds on other planets, thermodynamic models and abundance constraints allow us to postulate the possible altitudes and depths of clouds in various planets [Atreya, 1986]. Early modeling work further constrains the location of electric charge centers in the different planets [Yair et al., 2008, and references therein].

\section{Results}

\subsection{Earth}

[10] In order to calibrate the model prior to applying it to alien conditions we recalculated the predicted occurrence heights of sprites in the terrestrial atmosphere, in a manner similar to that presented by Pasko et al. [1997]. The thunderstorm charge distribution assumes that a negative charge is located at $5 \mathrm{~km}$ and an equal and opposite charge resides at $10 \mathrm{~km}$, typical altitudes for sprite-producing winter thunderstorms in Japan and the eastern Mediterranean [Ganot et al., 2007]. This dipole description significantly simplifies the multilayer charge structure, typical of sprite-producing summer supercells [Stolzenburg et al., 2001; Lyons et al., 2008], but for the purpose of the present study it is sufficient. After the positive cloud-to-ground flash that removes the upper positive charge center $(+\mathrm{CG})$ the negative screening charge center remains at approximately cloud top, leading to the short-lived QE field in the space between cloud top and the ionosphere. The results are presented in Figure 1 for different values of Q. For an initial configuration of two 50C charges placed at 5 and $10 \mathrm{~km}$ (a postulated charge moment change of $10 \mathrm{~km} \times 50 \mathrm{C}=500 \mathrm{C} \times \mathrm{km}$ by the flash), the conventional breakdown field is exceeded at $\sim 84 \mathrm{~km}$, where the conventional breakdown field is $10.26 \mathrm{~V} \mathrm{~m}^{-1}$. For a charge of $100 \mathrm{C}$ $(\mathrm{CMC}=1000 \mathrm{C} \times \mathrm{km})$ this threshold is achieved at $79 \mathrm{~km}$ $\left(\mathrm{E}_{\mathrm{k}}=26.6 \mathrm{~V} \mathrm{~m}^{-1}\right)$. These values are in good agreement with Pasko et al. [1997], who used a $1000 \mathrm{C} \times \mathrm{km}$ charge moment change for evaluating sprite onset altitudes.

\subsection{Venus}

[11] Venus is a terrestrial planet completely covered by a thick layer of sulfuric acid clouds in three layers spanning the $50-70 \mathrm{~km}$ altitude range above the surface [Markiewicz 


\section{Earth - charge height $10 \mathrm{~km}$}

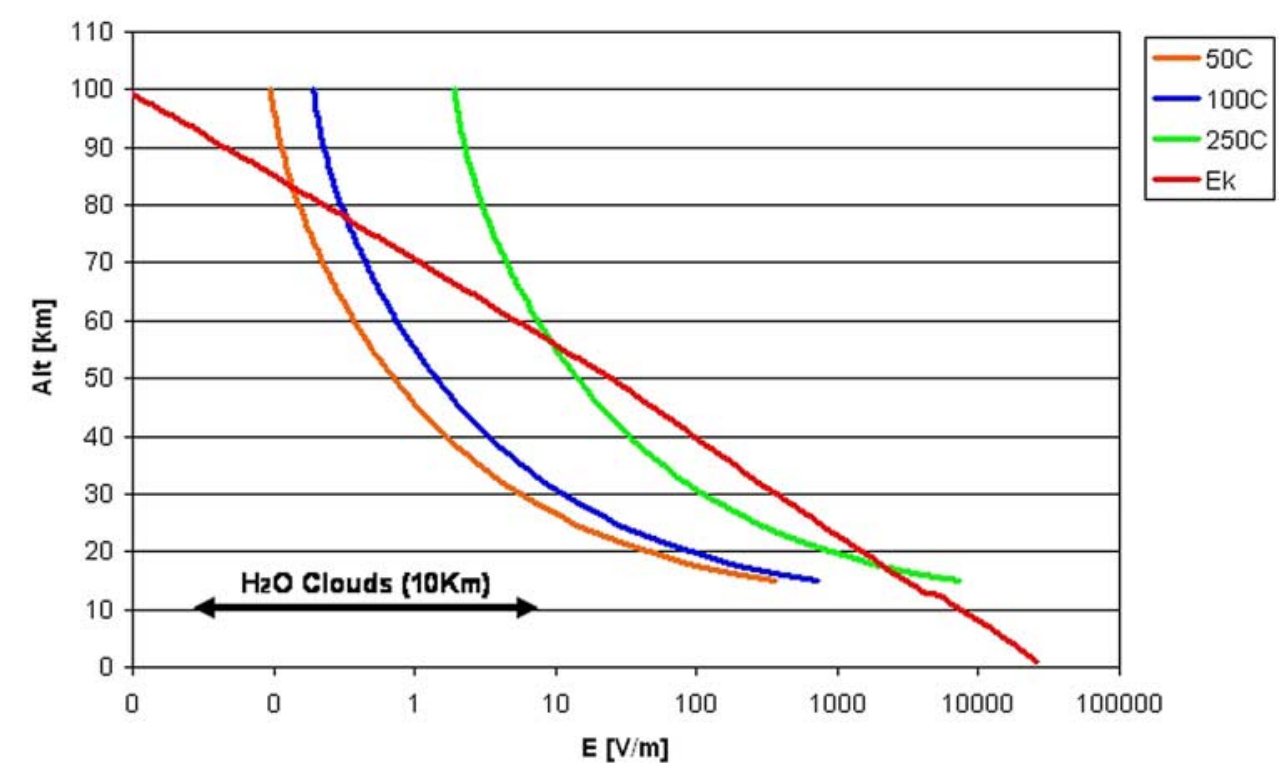

Figure 1. The electrostatic field above typical terrestrial wintertime sprite-producing thundercloud. Monopole structure with 50,100, and $250 \mathrm{C}$ located at $10 \mathrm{~km}$. Where the conventional breakdown field (brown) crosses the E field, a sprite can potentially occur.

et al., 2007]. The ionospheric layer peaks at $140 \mathrm{~km}$ with an electron density $\sim 4 \times 10^{5} \mathrm{~cm}^{-3}$ [Pätzold et al., 2007]. The huge surface atmospheric pressure $(\sim 9 \mathrm{MPa})$ renders the existence of cloud-to-ground discharges from the high-level sulfuric acid clouds $\left(\mathrm{Z}_{\mathrm{s}} \sim 50\right.$ to $\left.70 \mathrm{~km}\right)$ practically impossible owing to the high value of the required field for electrical breakdown. Thus, it is highly likely that lightning activity on Venus would be composed entirely of intracloud (IC) discharges, either between clouds at the same layer or between two separated cloud decks. On the basis of the Cassini spacecraft data, Gurnett et al. [2001] stated that such IC discharges would be slow to build up and would exhibit different characteristics compared to their terrestrial analogs. A slow discharge would meet the requirement of the QE model [Pasko et al., 1997], and on the basis of the above-cloud conductivity profile used by Pechony and Price [2004] the penetration of thundercloud induced electric fields into the upper atmosphere would last the order of $0.1 \mathrm{~s}$ before electrostatic relaxation. The potential occurrence altitudes of sprites for several values of charge, placed at a representative altitude of the cloud deck at $50 \mathrm{~km}$, are presented in Figure 2. The threshold for conventional breakdown is exceeded at $90 \mathrm{~km}\left(729 \mathrm{~V} \mathrm{~m}^{-1}\right)$ and $84 \mathrm{~km}$ $\left(2862 \mathrm{~V} \mathrm{~m}^{-1}\right)$ for charges of 100 and $250 \mathrm{C}$, respectively. Thus, for an IC flash with a charge moment change of $100 \mathrm{C} \times 5 \mathrm{~km}=500 \mathrm{C} \times \mathrm{km}$ occurring between the two lower cloud layers (presumably separated by $5 \mathrm{~km}$ ), a sprite can be triggered approximately at an altitude $90 \mathrm{~km}$ above ground, $\sim 20 \mathrm{~km}$ above the tops of the upper most cloud layer. As can be expected, larger accumulation of charge would result in a sprite at lower altitudes and closer to the cloud tops, leaving just a narrow margin for attempted above-limb spacecraft observations.
[12] The climatology of lightning activity in Venus is still largely unknown, and hence no latitudinal dependence of sprite occurrence can be predicted. Since the clouds of Venus are assumed to posses a low mass content, it is hard to envision very large accumulations of charge due to the low efficiency of known charge separation mechanisms [Levin et al., 1983]. Furthermore, based on the Venus Monitoring Camera on board Venus Express, the depth of subsolar induced convection seems to be shallower than previously assumed [Markiewicz et al., 2007], and it does not penetrate into the middle and lower cloud decks. Still, this does not rule out the possibility that unknown types of charge generation processes do take place in the deep clouds of Venus that eventually lead to lightning and consequently to sprites.

\subsection{Mars}

[13] Mars does not posses convective $\mathrm{CO}_{2}$ or $\mathrm{H}_{2} \mathrm{O}$ clouds with sufficient vertical motions and particle concentrations to separate electrical charges and build up sustained electric fields that will lead to conventional breakdown and lightning. Mars is frequented by dust storms, from local convectively unstable dust devils to regional storms and planetary scale events. Cantor et al. [2001] showed that dust storms are frequently spawned at the edges of the two polar cap, at the base of elevated regions in the northern Martian hemisphere, near the polar hood during northern fall and at midlatitudes in both hemispheres. Charging in dust storms that occur in the lower atmosphere was simulated in laboratory experiments and modeled extensively, and it is expected that significant charge is generated within them by triboelectric charging [Sternovsky et al., 2002; Krauss et al., 2003] and by attachment of galactic cosmic ray-induced ionization products [Michael et al., 2008]. The numerical simulation by Melnik and Parrot [1998] suggested that this charging process is very 


\section{Venus - charge height $50 \mathrm{~km}$}

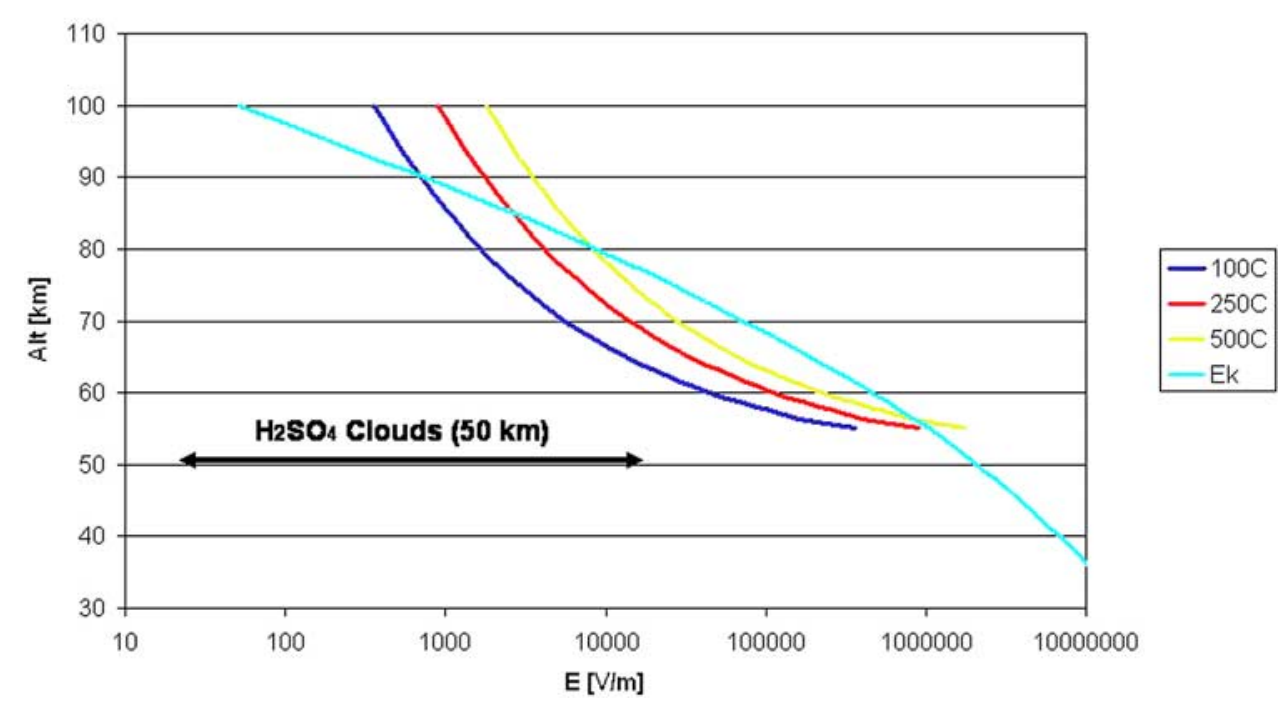

Figure 2. The electrostatic field above a Venusian charge configuration placing opposite and equal charges at the lower $(40 \mathrm{~km})$ and middle $(50 \mathrm{~km})$ cloud decks. The critical breakdown field is surpassed at $92 \mathrm{~km}$ (for $500 \mathrm{C}$ ) and $100 \mathrm{~km}$ (for $100 \mathrm{C}$ ).

efficient and generates local fields within the dust devil of $\sim 20 \mathrm{kV} \mathrm{m}{ }^{-1}$ which are sufficient to lead to breakdown (it should be pointed out that the coefficients used by Melnik and Parrot [1998] for $\mathrm{CO}_{2}$ breakdown were based on Paschen parameters, which may not be applicable in large gap discharges such as expected inside dust storms with several km size). Farrell et al. [1999] maintain that larger storms, of the order of $\sim 5 \mathrm{~km}$, are unable to sustain large amounts of charge and will initiate corona and glow discharge. Our calculations show that even for the low case of $Q=10 \mathrm{C}$ located at $10 \mathrm{~km}$ above the surface, the conventional breakdown is surpassed within the dust cloud and not above it. Larger charges will have a similar effect, suggesting that sprite-like discharges on Mars will not occur above the charge center.

\subsection{Titan}

[14] Titan is the only moon in the solar system that has a thick atmosphere, which is dominated by nitrogen and methane and has a surface pressure of 1.5 bars and a temperature of $94 \mathrm{~K}$. A recent review by Lorenz [2008] describes the complex hydrological circle on Titan, with convective methane clouds producing occasional flash floods. Such clouds were intermittently observed over Titan's south pole in 2004 and 2005 [Rannou et al., 2006] and are assumed to contain sufficient mass loading for particle interaction to be significant. The conductivity of Titan's atmosphere at altitudes above the troposphere was studied by Borucki et al. [1987, 2006] and Whitten et al. [2007], and is often modeled as increasing with height to values $\sim 10^{-8} \mathrm{~S} \mathrm{~m}^{-1}$ at $80 \mathrm{~km}$ implying a relaxation time of $1 \mathrm{~ms}$ for any lightning-induced QE field. We assumed a convective methane cloud possessing a monopole charge structure, with the negative charge center located $20 \mathrm{~km}$ above the ground, in accordance with the numerical simulations of cloud charging and lightning generation presented by Tokano et al. [2001]. We used three different values of total charge: $50 \mathrm{C}, 100 \mathrm{C}$, and even the highly unrealistic amount of $250 \mathrm{C}$. The results (Figure 3) show that electrical breakdown may be achieved within the cloud (indicating the possibility for lightning) but the resulting above-cloud QE electric field fails to surpass the conventional breakdown value even at an altitude of $200 \mathrm{~km}$, meaning that no sprites can be expected in that atmosphere.

\subsection{Jupiter}

[15] Jupiter is a gas giant with a hydrogen-helium atmosphere and lacks a solid surface. The ionosphere is found approximately $1000 \mathrm{~km}$ above the 1-bar level (which is commonly used as a reference even though it lacks any special meteorological significance) with electron concentrations $\sim 10^{5} \mathrm{~cm}^{-3}$, and a second peak at $\sim 2000 \mathrm{~km}$ with $\sim 10^{4} \mathrm{~cm}^{-3}$ electron concentration [Hinson et al., 1997]. Inevitably, all lightning activity in Jupiter is intracloud, believed to originate within the deep convective water cloud layer [Williams et al., 1983]. These mixed-phase clouds can be several tens of kilometers deep and can be very efficient in charge separation, able to rapidly generate strong electric fields that surpass the critical value and produce very energetic lightning [Yair et al., 1995]. The inner boundary (in terms of the electrical capacitor concept of the planetary global circuit it is a perfect electric conductor) is determined by the conductivity profile and the corresponding skin depth. In the ELF range, where the lightning produced Schumann Resonances are commonly used to detect electrical activity [Yang et al., 2006], a conductivity of $\sim 0.01 \mathrm{~S}$ $\mathrm{m}^{-1}$ provides a skin depth of a few $\mathrm{km}$, which is much less than cavity thickness. On Jupiter, such conductivity is reached at $\sim 0.96$ Jupiter radius which corresponds to $\sim 150$ kbar, very deep below the $\mathrm{H}_{2} \mathrm{O}$ clouds which are located between 5 and 2 bars [Simões et al., 2008]. In this case equation (2) can be simplified to that of a monopole in free space. For the model calculations of the above-cloud 
Titan - charge height $25 \mathrm{~km}$

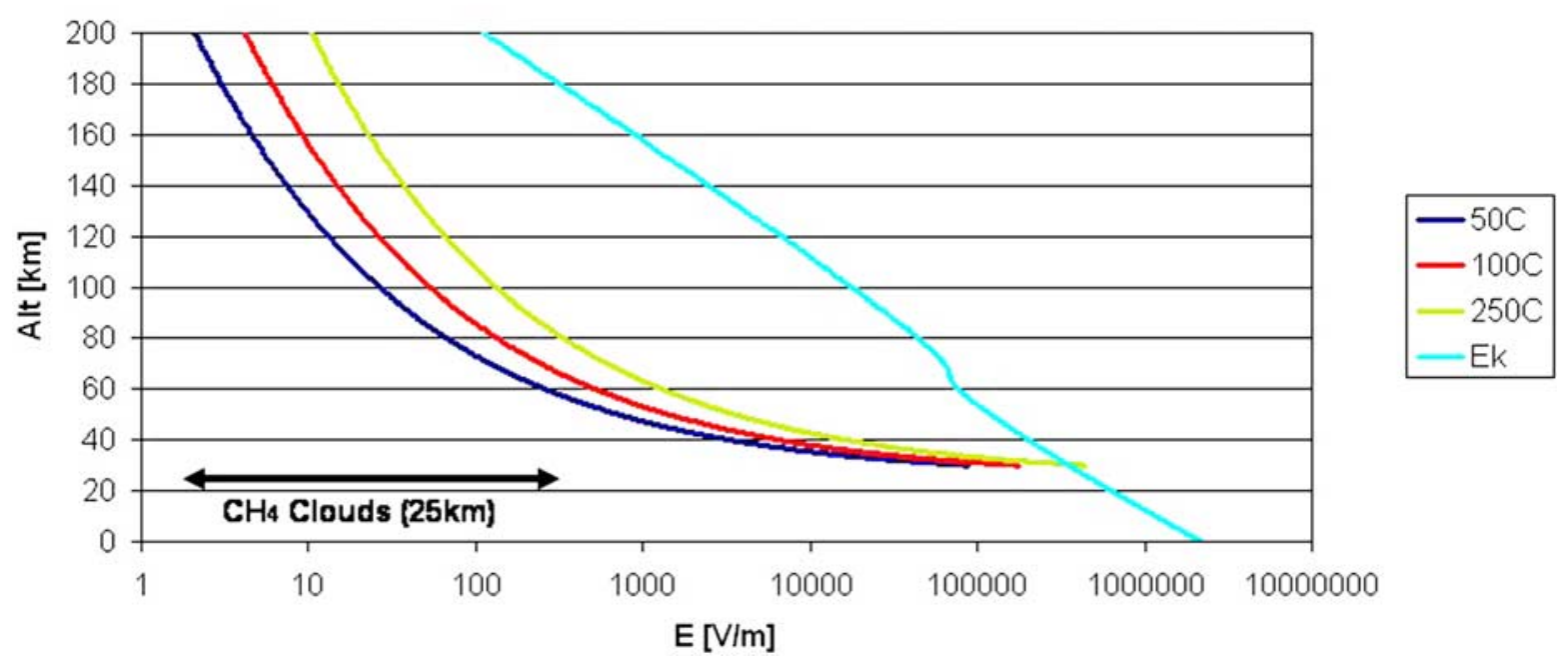

Figure 3. The electrostatic field above a Titan thundercloud possessing a negative charge located at $25 \mathrm{~km}$. Even at high values of total charge, the breakdown field is not exceeded and sprites cannot occur above the cloud.

electrostatic field for a Jovian thundercloud we placed a single charge center containing 100,500 , and $1000 \mathrm{C}$ within the deep $\mathrm{H}_{2} \mathrm{O}$ thundercloud which is supposed to reside between 5 and 3 bars [Yair et al., 1995]. The results suggest that for a $1000 \mathrm{C}$ charge located $30 \mathrm{~km}$ below the 1-bar pressure level (where Gibbard et al. [1995] and Yair et al.
[1998] showed the upper charge center in the $\mathrm{H}_{2} \mathrm{O}$ cloud reside) a sprite can be ignited at an altitude $\sim 280 \mathrm{~km}$ above the 1-bar level, approximately $100 \mathrm{~km}$ above the top visible $\mathrm{NH}_{3}$ cloud layer (Figure 4). A lower charge accumulation in the thundercloud $(100 \mathrm{C})$ will be manifested in higher generation altitudes for Jovian sprites, still below the iono-

\section{Jupiter - charge height $-30 \mathrm{~km}$}

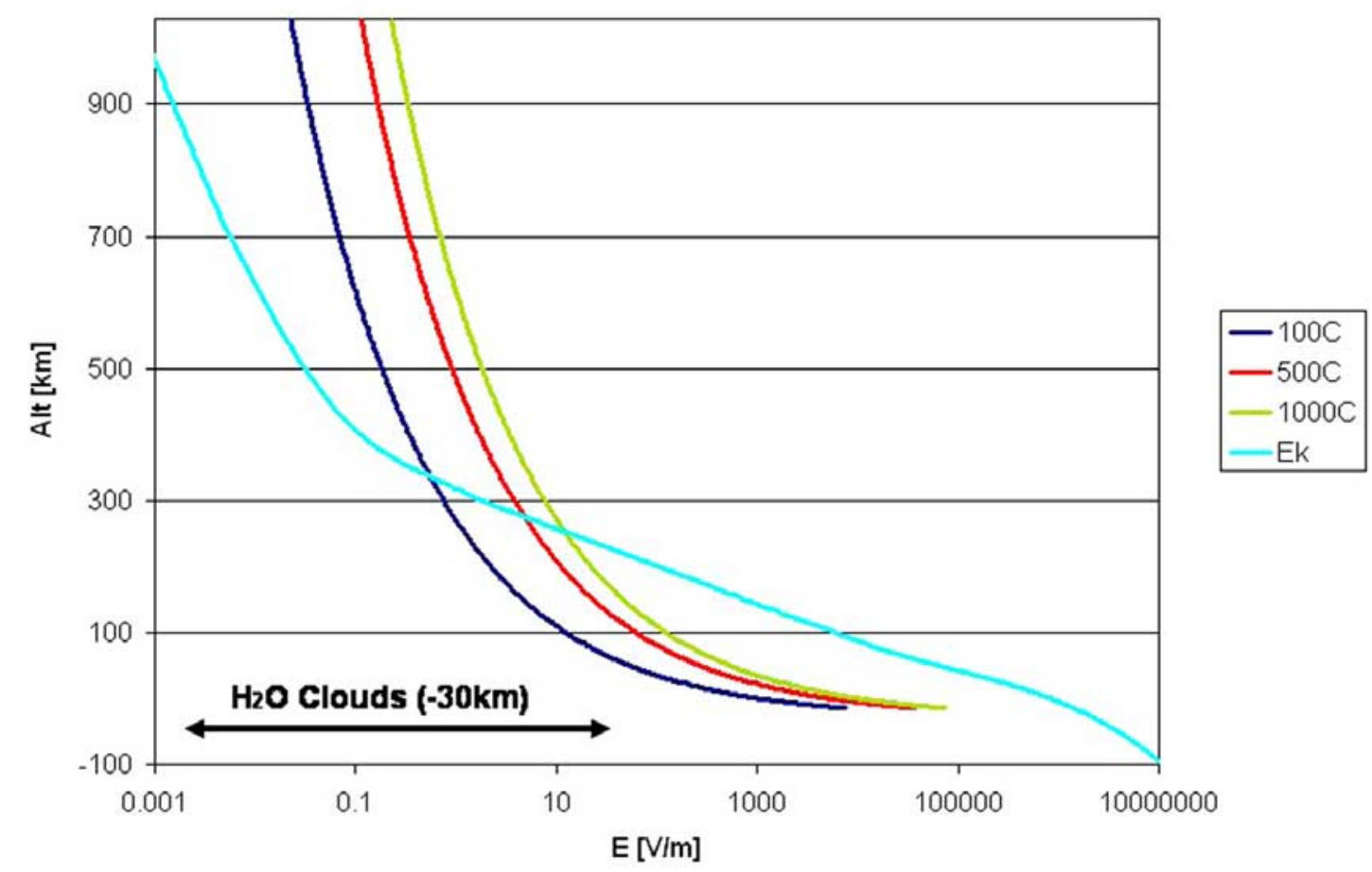

Figure 4. The electrostatic field above a Jovian thundercloud possessing a negative charge located $30 \mathrm{~km}$ below the 1-bar pressure level. The field is exceeded for a realistic charge of $1000^{\circ} \mathrm{C}$ at an altitude of $280 \mathrm{~km}$ above the 1-bar level. 
sphere. Since lightning in Jupiter are absent in equatorial regions and are mostly located at middle and high latitudes, we would expect Jovian sprites to appear above the clouds in these regions, whenever a strong convective system evolves. No seasonal dependence for such cloud structures had been reported.

\section{Expected Emissions Based on Laboratory Experiments}

[16] The early experimental work of Borucki and McKay [1987] was conducted for predicting the optical efficiencies of various atmospheres in order to assess their capability to allow lightning light to emanate from the deep atmosphere so that it can be detected by a sensor on an orbiting spacecraft. The results showed that the fraction of the energy in lightning discharge channels that is radiated in the visible spectrum is similar for Earth, Venus, and Titan, but quite different for Jupiter. Additional laboratory data on the possible spectrum of lightning in other planets was obtained by Laser-Induced Plasma (LIP) experiments conducted by Borucki et al. [1996]. These showed the main spectral features of high-energy discharges in various gas mixtures representing the atmospheres of Venus, Jupiter, and Titan. However, these experiments mimicked the highcurrent high-temperature lightning channel, and are different from the low-current low-temperature nature of sprites.

[17] Experiments in low-temperature nonequilibrium discharges were conducted by Williams et al. [2006], who produced what they termed "sprite in a bottle" using DC currents inside an air-filled glow discharge tube at pressures of 0.01 to 1 torr at room temperature. The current densities in the tube were $\sim 1 \mathrm{~mA} \mathrm{~m}^{-2}$ and the resulting spectra were in reasonable agreement with those observed in nature, as reported by Hampton et al. [1996]. The radiance of the $\mathrm{N}_{2} 1 \mathrm{P}$ line was found to be roughly proportional to the applied current density, where a $10 \mathrm{~mA} \mathrm{~m}{ }^{-2}$ current density corresponds to a brightness of $1 \mathrm{MR}$, considered in the upper limit for sprite brightness [Hampton et al., 1996, Figure 8]. Similar experiments were conducted by Goto et al. [2007] for different atmospheric pressures, ranging between 0.0075 and 7.0 torr $\left(\sim 10^{-2} \mathrm{mb}\right.$, approximately equivalent to $80 \mathrm{~km}$ altitude, to $9.33 \mathrm{mb}$ which is equivalent to $31 \mathrm{~km}$ altitude). They used a high voltage electrode suspended inside a Pyrex glass tube, with applied DC voltages of 50 and $100 \mathrm{kV}$. The obtained spectra between 550 and $800 \mathrm{~nm}$ showed a reasonable agreement with the results of Hampton et al. [1996]. The spectral distributions were shown to be independent of the relative humidity of the air, and displayed clear pressure dependence, with many lines becoming weak or disappearing as the pressure increases. In a recent work, Ohba et al. [2004] repeated the experiment for $\mathrm{CO}_{2}$ in order to simulate the Venusian atmosphere between 5 and 100 torr (6 to $133 \mathrm{mb}$ ), with 2 different voltages, 100 and $700 \mathrm{kV}$. At the high voltage, $\mathrm{CO}_{2}^{+}$bands were present at $354.5,383.8,404.8,426.8$, $434.4,465.9,512.9$, and $543.0 \mathrm{~nm}$, as well as the $\mathrm{H} \alpha$ $(656.2 \mathrm{~nm})$ and the OI line in $777.6 \mathrm{~nm}$. These emissions are in good agreement with the early experiments of Smyth [1931] that showed several emission bands of the FoxDuffendack-Barker system of $\mathrm{CO}_{2}^{+}$between 290 and $500 \mathrm{~nm}$, with prominent lines near 288, 405, and $427 \mathrm{~nm}$.
In Venus, other emission lines from $\mathrm{CO}$ and $\mathrm{OH}$ are also possible. This suggests that the dominant colors of Venusian sprites may be blue-green and red. From theoretical considerations, we can expect that for the hydrogen-helium atmospheres of Jupiter and Saturn strong sprite emissions from atomic hydrogen in $656 \mathrm{~nm}$ and from He near 447, 587 , and $706 \mathrm{~nm}$ (based on the NIST database atomic spectra). Molecular hydrogen emissions may also be present, such as the Lyman and Werner bands in the EUV. Sprites on Titan, should they exist, would display the same spectra of terrestrial ones, since molecular nitrogen is the main component in both atmospheres.

[18] These glow discharge experiments are physically similar to sprites, as in both cases the emissions are due to the collision of field accelerated electrons with gas molecules at room temperature. Therefore similar spectral lines occur. However, the electric field in the positive column of a long glow discharge is much lower than the enhanced field at the head of a streamer; in particular, these fields are well below or well above $\mathrm{E}_{\mathrm{k}}$. Images with high temporal resolution show the same glowing streamer heads in experiments [Ebert et al., 2006] and in sprite observations [Stenbaek-Nielsen et al., 2007; Stenbaek-Nielsen and McHarg, 2008]. The emissions from these heads are characteristic for the high local fields and electron energies in the streamer head, and therefore the relative intensity of spectral emissions differs between glow and streamer discharges. Another difference is due to the fact that in a stationary DC glow discharge at low fields, excitations can occur in two or more steps and are therefore strongly pressure dependent, while two-step processes are unlikely in the rapidly propagating high field zone at a streamer head, and spectral emissions therefore depend much less on pressure or density. Therefore, the glow discharge experiments give an indication on the expected emission lines, but relative line intensities will have to be deduced from time resolved streamer experiments, or from theory.

\section{Discussion}

[19] Model calculations predict the appearance of sprites in the upper atmospheres of Venus and Jupiter on the basis of reasonable assumptions on the amount of charge that may be present in the hypothetical thunderclouds in their atmospheres. The resultant spectral emissions for sprites in the atmospheres of other planets can be searched for by orbiting spacecraft observing the night side of the planet toward the limb, as was practiced during the MEIDEX sprite campaign from the space shuttle [Yair et al., 2003] and as being operationally conducted by the ISUAL instrument on board the FORMOSAT-2 satellite [Kuo et al., 2005; Cummer et al., 2006]. In these missions, sprites were recorded above the Earth's limb from ranges of $1800-3000 \mathrm{~km}$. This is a consequence of the low absorption of sprite light by the atmosphere that enabled enough photons to reach the onboard detectors. During the MEIDEX, the measured brightness of sprites was in the range of $0.3-1.7$ megaRayleigh (MR; one Rayleigh is equal to $7.96 \times 10^{4}$ photons $\mathrm{s}^{-1} \mathrm{~m}^{-2} \mathrm{sr}^{-1}$ ) in the $665 \pm 50 \mathrm{~nm}$ range and $1.44-1.7 \mathrm{MR}$ in the $860 \pm 50 \mathrm{~nm}$ range [Yair et al., 2004], typical of emissions of the $\mathrm{N}_{2} 1 \mathrm{P}$ group. 
[20] For Venus, the Japanese Planet-C mission [Nakamura et al., 2007; Takahashi et al., 2008] is designed to carry the Lightning and Airglow Camera (LAC) which will be used to observe lightning on Venus even if they are less bright by a factor of 100 compared to terrestrial flashes, when viewed from a $100 \mathrm{~km}$ altitude. The LAC will have multispectral capabilities and will cover the oxygen lines in $777.4 \mathrm{~nm}(\mathrm{OI}$, related to lightning) and in $552.5 \mathrm{~nm}\left[\mathrm{O}_{2}\right.$ Herzberg II], $557.7 \mathrm{~nm}[\mathrm{OI}]$ and 630.0 [OI], which are airglow emissions. Since the field of view is $16^{\circ}$, it is highly likely that any sprite emission above the cloud tops will be detected by the instrument as it observes the limb. The fact that no optical emissions from Venus lightning had been thus far reliably detected means that they may be weak or completely hidden owing to absorption by the high-level clouds. This poses an interesting challenge for the Planet-C mission, namely, to indirectly infer the existence of lightning in Venus based on their sprite fingerprints. For Mars, the possibility that corona or other types of discharges occur inside dust devils and in large-scale dust storms can be optically verified by sensitive cameras on board future landers. The possibility that such discharges can be remotely sensed by orbiting spacecraft is unclear owing to absorption and obscuration by the dust. However, if sparks do emanate from the upper parts of the dust clouds upward into the free atmosphere (upward flashes had been reported lately on Earth) [Krehbiel et al., 2008] they can be sought for by nighttime oblique observations of the dust column, in order to allow escaping photons to reach the sensor.

[21] The duration and morphology of alien sprites will strongly depend on the nature of the parent lightning and on the properties of the atmosphere. Once the critical breakdown field had been surpassed locally, electron avalanches can evolve into streamers if the ambient (prebreakdown) electron density is appropriate; the maximal local field depends on the temporal behavior of the lighting strokes and on spatially varying dielectric relaxation times, which in turn depend on the ambient conductivity. These conditions are discussed in detail by Pasko et al. [1998, 2002] for terrestrial sprites. We presently have little information on these parameters for other planets, yet some insights can be deduced from observations and laboratory experiments that use high-speed photography to study electrical sparks and streamers in various gas mixtures based on similarity laws and the analogy drawn between sprites and gas discharge sparks. Stenbaek-Nielsen et al. [2007] and McHarg et al. [2007] have shown that the tips of sprites are glowing balls that move rapidly $\left(10^{7} \mathrm{~m} \mathrm{~s}^{-1}\right.$.) and typically brighten as they travel up or down, with brightness exceeding $60 \mathrm{MR}$. The same structure was seen at the tips of streamers produced in laboratory experiments [Ebert et al., 2006]. Recently, Briels et al. [2006] reported on the properties of streamers with diameters varying gradually between 0.2 and $2.5 \mathrm{~mm}$, as recorded by an iCCD camera with nanosecond resolution. In another work Briels et al. [2008] showed that similarity laws apply for the morphology of streamers at varying gas densities, and Nijdam et al. [2008] used the same system to study the 3-D structure and the branching of streamers. In an appropriate vacuum chamber, such experiments can be replicated in the appropriate planetary gas mixtures, in order to elucidate the nature of sprites occurring in these atmospheres. Present measurements in pure nitro- gen and pure argon already indicate that streamer properties (inception, width, length, branching) largely depend on gas composition. This will be a subject for future research.

[22] Acknowledgment. This research was supported by the Israeli Science Foundation, grant 117/09.

\section{References}

Aplin, K. (2006), Atmospheric electrification in the solar system, Surv. Geophys., 27(1), 63-108, doi:10.1007/s10712-005-0642-9.

Atreya, S. K. (1986), Atmospheres and Ionospheres of the Outer Planets and Their Satellites, 224 pp., Springer, Berlin.

Baines, K. H., et al. (2007), Polar lightning and decadal-scale cloud variability on Jupiter, Science, 318, 226-229, doi:10.1126/science.1147912.

Barrington-Leigh, C. P., U. S. Inan, M. Stanley, and S. A. Cummer (1999), Sprites triggered by negative lightning discharges, Geophys. Res. Lett., $26,3605-3608$

Borucki, W. J., and J. A. Magalhaes (1992), Analysis of Voyager 2 images of Jovian lightning, Icarus, 96, 1-14, doi:10.1016/0019-1035(92)90002-O.

Borucki, W. J., and C. P. McKay (1987), Optical efficiencies of lightning in planetary atmospheres, Nature, 328, 509-510, doi:10.1038/328509a0.

Borucki, W. J., Z. Levin, R. C. Whitten, R. G. Keesee, L. A. Capone, O. B. Toon, and J. Dubach (1987), Predictions of the electrical conductivity and charging of the aerosols in Titan's atmosphere, Icarus, 72, 604-619, doi:10.1016/0019-1035(87)90056-X

Borucki, W. J., C. P. McKay, D. Jebens, H. S. Lakkaraju, and C. T. Vanajakshi (1996), Spectral irradiance measurements of simulated lightning in planetary atmospheres, Icarus, 123, 336-344, doi:10.1006/icar.1996.0162.

Borucki, W. J., R. C. Whitten, E. L. O. Bakes, E. Barth, and S. Tripathi (2006), Predictions of the electrical conductivity and charging of the aerosols in Titan's atmosphere, Icarus, 181, 527-544.

Briels, T. M. P., J. Kos, E. M. van Veldhuizen, and U. Ebert (2006), Circuit dependence of the diameter of pulsed positive streamers in air, J. Phys. D Appl. Phys., 39, 5201-5210, doi:10.1088/0022-3727/39/24/016.

Briels, T. M. P., E. M. van Veldhuizen, and U. Ebert (2008), Positive streamers in air and nitrogen of varying density: Experiments on similarity laws, J. Phys. D Appl. Phys., 41, 234008, doi:10.1088/0022-3727/41/23/234008.

Cantor, B. A., P. B. James, M. Caplinger, and M. J. Wolff (2001), Martian dust storms: 1999 Mars Orbiter Camera observations, J. Geophys. Res., 106, 23,653-23,687, doi:10.1029/2000JE001310.

Cooray, V. (2003), Mechanism of electrical dischargesThe Lightning Flash, IEE Power Energy Ser, vol. 34, edited by V. Cooray, pp. 45-126, Inst. Electr. Eng., London.

Cummer, S. A., and W. A. Lyons (2005), Implications of lightning charge moment changes for sprite initiation, J. Geophys. Res., 110, A04304, doi:10.1029/2004JA010812.

Cummer, S. A., H. U. Frey, S. B. Mende, R.-R. Hsu, H.-T. Su, A. B. Chen, H. Fukunishi, and Y. Takahashi (2006), Simultaneous radio and satellite optical measurements of high-altitude sprite current and lightning continuing current, J. Geophys. Res., 111, A10315, doi:10.1029/2006JA011809.

Desch, S. J., W. J. Borucki, C. T. Russell, and A. Bar-Nun (2002), Progress in planetary lightning, Rep. Prog. Phys., 65, 955-997, doi:10.1088/00344885/65/6/202.

Ebert, U., and D. D. Sentman (Eds.) (2008), Streamers, sprites, leaders, lightning: From micro- to macroscales, J. Phys. D Appl. Phys., 41, 230301, doi:10.1088/0022-3727/41/23/230301.

Ebert, U., C. Montijn, T. M. P. Briels, W. Hundsdorfer, B. Meulenbroek, A. Roccoand, and E. M. van Veldhuizen (2006), 2006: The multiscale nature of streamers, Plasma Sources Sci. Technol., 15, S118-S129, doi:10.1088/0963-0252/15/2/S14.

Farrell, W. M., et al. (1999), Detecting electrical activity from Martian dust storms, J. Geophys. Res., 104, 3795-3801, doi:10.1029/98JE02821.

Fischer, G., D. A. Gurnett, W. S. Kurth, W. M. Farrell, M. L. Kaiser, and P. Zarka (2007), Nondetection of Titan lightning radio emissions with Cassini/RPWS after 35 close Titan flybys, Geophys. Res. Lett., 34, L22104, doi:10.1029/2007GL031668.

Franz, R. C., R. J. Nemzek, and J. R. Winckler (1990), Television image of a large upward electric discharge above a thunderstorm, Science, 249, $48-51$, doi:10.1126/science.249.4964.48

Füllekrug, M., and M. J. Rycroft (2006), The contribution of sprites to the global atmospheric electric circuit, Earth Planets Space, 58, 1193-1196. Ganot, M., Y. Yair, C. Price, B. Ziv, Y. Sherez, E. Greenberg, A. Devir, and R. Yaniv (2007), First detection of transient luminous events associated with winter thunderstorms in the eastern Mediterranean, Geophys. Res. Lett., 34, L12801, doi:10.1029/2007GL029258.

Gerken, E. A., U. S. Inan, and C. P. Barrington-Leigh (2000), Telescopic observations of sprites, Geophys. Res. Lett., 27, 2637-2640, doi:10.1029/ 2000GL000035. 
Gibbard, S., E. H. Levy, and J. I. Lunine (1995), Generation of lightning in Jupiter's water cloud, Nature, 378, 592-595.

Gordillo-Vázquez, F. J. (2008), Air plasma kinetics under the influence of sprites, J. Phys. D Appl. Phys., 41, 234016, doi:10.1088/0022-3727/41/23/ 234016.

Goto, Y., Y. Ohba, and K. Narita (2007), Optical and spectral characteristics of low pressure air discharges as sprite models, J. Atmos. Electr., 27, $105-112$.

Gurnett, D. A., W. S. Kurth, A. Roux, R. Gendrin, C. F. Kennel, and J. F. Bolton (1991), Lightning and plasma wave observations from the Galileo flyby of Venus, Science, 253, 1522-1525, doi:10.1126/science.253.5027. 1522 .

Gurnett, D. A., P. Zarka, R. Manning, W. S. Kurth, G. B. Hospodarski, F. T. Averkamp, M. L. Kaiser, and W. M. Farrell (2001), Non-detection at Venus of high-frequency radio signals characteristic of terrestrial lightning, Nature, 409, 313-315, doi:10.1038/35053009.

Gurnett, D. A., et al. (2005), Radio and plasma wave observations at Saturn from Cassini's approach and first orbit, Science, 307, 1255-1259, doi:10.1126/science. 1105356

Hampton, D. L., M. J. Heavner, E. M. Wescott, and D. D. Sentman (1996) Optical spectral characteristics of sprites, Geophys. Res. Lett., 23, 89-92, doi:10.1029/95GL03587.

Hinson, D. P., et al. (1997), Jupiter's ionosphere: Results from the first Galileo radio occultation experiment, Geophys. Res. Lett., 24, 2107-2109, doi:10.1029/97GL01608

Hiraki, Y., and H. Fukunishi (2006), Theoretical criterion of charge moment change by lightning for initiation of sprites, J. Geophys. Res., 111, A11305, doi:10.1029/2006JA011729.

Jackson, J. D. (1975), Classical Electrodynamics, 2nd ed., Wiley, New York.

Krasnopolsky, V. A. (2006), A sensitive search for nitric oxide in the lower atmospheres of Venus and Mars: Detection on Venus and upper limit for Mars, Icarus, 182, 80-91, doi:10.1016/j.icarus.2005.12.003.

Krauss, C. E., M. Hor'anyi, and S. Robertson (2003), Experimental evidence for electrostatic discharging of dust near the surface of Mars, New J. Phys., 5, 70.1-70.9.

Krehbiel, P. R., J. A. Riousset, V. P. Pasko, R. J. Thomas, W. Rison, M. A Stanley, and H. E. Edens (2008), Upward electrical discharges from thunderstorms, Nat. Geosci., 1, 233-237, doi:10.1038/ngeo162.

Ksanfomality, L. V. (1980), Venera 9 and 10: Thermal radiometry, Icarus, 41, 36-64, doi:10.1016/0019-1035(80)90158-X

Kuo, C.-L., R. R. Hsu, A. B. Chen, H. T. Su, L. C. Lee, S. B. Mende, H. U. Frey, H. Fukunishi, and Y. Takahashi (2005), Electric fields and electron energies inferred from the ISUAL recorded sprites, Geophys. Res. Lett., 32, L19103, doi:10.1029/2005GL023389.

Levin, Z., W. B. Borucki, and O. B. Toon (1983), Lightning generation in planetary atmospheres, Icarus, 56, 80-115, doi:10.1016/0019-1035(83) 90129-X.

Little, B., C. D. Anger, A. P. Ingersoll, A. R. Vasavada, D. A. Senske, H. Herbert Breneman, W. J. Borucki, and The Galileo SSI Team (1999), Galileo images of lightning on Jupiter, Icarus, 142, 306-323, doi:10.1006/ icar.1999.6195.

Lorenz, R. D. (2008), The changing face of Titan, Phys. Today, 61, 34-39, doi:10.1063/1.2970210

Lyons, W. A., S. A. Cummer, M. A. Stanley, G. R. Huffins, K. C. Wiens, and T. E. Nelson (2008), Supercells and sprites, Bull. Am. Meteorol. Soc., $89,1165-1174$.

Markiewicz, W. J., D. V. Titov, S. S. Limaye, H. U. Keller, N. Ignatiev, R. Jaumann, N. Thomas, H. Michalik, R. Moissi, and P. Russo (2007), Morphology and dynamics of the upper cloud layer of Venus, Nature, 450, 633-636, doi:10.1038/nature06320.

McHarg, M. G., H. C. Stenbaek-Nielsen, and T. Kammae (2007), Observations of streamer formation in sprites, Geophys. Res. Lett., 34, L06804, doi:10.1029/2006GL027854.

Melnik, O., and M. Parrot (1998), Electrostatic discharge in Martian dust storms, J. Geophys. Res., 103, 29,107-29,117, doi:10.1029/98JA01954.

Michael, M., S. N. Tripathi, and S. K. Mishra (2008), Dust charging and electrical conductivity in the day and nighttime atmosphere of Mars, J. Geophys. Res., 113, E07010, doi:10.1029/2007JE003047.

Morrill, J., et al. (2002), Electron energy and electric field estimates in sprites derived from ionized and neutral $\mathrm{N}_{2}$ emissions, Geophys. Res Lett., 29(10), 1462, doi:10.1029/2001GL014018.

Nakamura, M., et al. (2007), Planet-C: Venus climate orbiter mission of Japan, Planet. Space Sci., 55, 1831-1842, doi:10.1016/j.pss.2007.01.009.

Neubert, T., et al. (2008), Recent results from studies of electric discharges in the mesosphere, Surv. Geophys., 29(2), 71-137, doi:10.1007/s10712008-9043-1.

Nijdam, S., J. S. Moerman, T. M. P. Briels, E. M. van Veldhuizen, and U. Ebert (2008), Stereo-photography of streamers in air, Appl. Phys. Lett., 92, 101502, doi:10.1063/1.2894195.
Ohba, Y., H. Koriyama, Y. Sato, and Y. Goto (2004), Spectral measurements of long gap carbon dioxide discharge by 1 MVIG (in Japanese), Proc. Soc. Atmos. Electr. Jpn., 64, 123-131.

Ohkubo, A., H. Fukunishi, Y. Takahashi, and T. Adachi (2005), VLF/ELF sferic evidence for in-cloud discharge activity producing sprites, Geophys. Res. Lett., 32, L04812, doi:10.1029/2004GL021943.

Pasko, V. P. (2007), Red sprite discharges in the atmosphere at high altitude: The molecular physics and the similarity with laboratory discharges, Plasma Sources Sci. Technol., 16, S13-S29, doi:10.1088/0963-0252/ $16 / 1 / \mathrm{S} 02$.

Pasko, V. P., U. S. Inan, and Y. N. Taranenko (1997), Sprites produced by quasi-electrostatic heating and ionization in the lower ionosphere, Geophys. Res. Lett., 22, 365-368.

Pasko, V. P., U. S. Inan, and T. F. Bell (1998), Spatial structure of sprites, Geophys. Res. Lett., 25, 2123-2126, doi:10.1029/98GL01242.

Pasko, V. P., U. S. Inan, and T. F. Bell (2001), Mesosphere-troposphere coupling due to sprites, Geophys. Res. Lett., 28, 3821-3824, doi:10.1029/ 2001GL013222.

Pasko, V., M. A. Stanley, J. D. Mathews, U. S. Inan, and T. G. Wood (2002), Electrical discharge from a thundercloud top to the lower ionosphere, Nature, 416, 152-154.

Pätzold, M., et al. (2007), The structure of Venus' middle atmosphere and ionosphere, Nature, 450, 657-660, doi:10.1038/nature06239.

Pechony, O., and C. Price (2004), Schumann resonance parameters calculated with a partially uniform knee model on Earth, Venus, Mars and Titan, Radio Sci., 39, RS5007, doi:10.1029/2004RS003056.

Raether, H. (1933), Die Entwicklung der Elektronenlawine in den Funkenkanal, Z. Phys., 112, 464-489.

Raizer, Y. P., G. M. Milikh, M. N. Shneidery, and S. V. Novakovskiz (1998), Long streamers in the upper atmosphere above thundercloud, J. Phys. D Appl. Phys., 31, 3255-3265, doi:10.1088/0022-3727/31/22/014.

Rannou, P., F. Montmessin, F. Hourdin, and S. Lebonnois (2006), The latitudinal distribution of clouds on Titan, Science, 311, 201-205, doi:10.1126/science. 1118424

Roussel-Dupré, R., J. J. Colman, E. Symbalisty, D. Sentman, and V. P. Pasko (2008), Physical processes related to discharges in planetary atmospheres, Space Sci. Rev., 137, 51-82, doi:10.1007/s11214-008-9385-5.

Russell, C. T., T. L. Zhang, M. Delva, W. Magnes, R. J. Stangeway, and H. Y. Wei (2007), Lightning on Venus inferred from whistler-mode waves in the ionosphere, Nature, 450, 661-662, doi:10.1038/nature05930.

São Sabbas, F. T. T., D. D. Sentman, E. M. Wescott, O. Pinto Jr., O. Mendes Jr., and M. J. Taylor (2003), Statistical analysis of space-time relationships between sprites and lightning, J. Atmos. Sol. Terr. Phys., 65, 525-535.

Sentman, D. D. (2004), Electrical breakdown parameters for neutral atmospheres of the solar system, paper presented at ISUAL workshop, Natl. Chen-Kung Univ., Tainan City, Taiwan.

Sentman, D. D., H. C. Stenbaek-Nielsen, M. G. McHarg, and J. S. Morrill (2008), Plasma chemistry of sprite streamers, J. Geophys. Res., 113, D11112, doi:10.1029/2007JD008941. (Correction, J. Geophys. Res., 113, D14399, doi:10.1029/2008JD010634.)

Simões, F., M. Rycroft, N. Renno, Y. Yair, K. L. Aplin, and Y. Takahashi (2008), Schumann resonances as a means of investigating the electromagnetic environment in the solar system, Space Sci. Rev., 137, 455-471, doi:10.1007/s11214-008-9398-0

Smyth, H. D. (1931), The emission spectrum of carbon dioxide, Phys. Rev. 38, 2000-2017, doi:10.1103/PhysRev.38.2000

Stenbaek-Nielsen, H. C., and M. G. McHarg (2008), High time-resolution sprite imaging: Observations and implications, J. Phys. D Appl. Phys., 41, 234009, doi:10.1088/0022-3727/41/23/234009.

Stenbaek-Nielsen, H. C., M. G. McHarg, T. Kanmae, and D. D. Sentman (2007), Observed emission rates in sprite streamer heads, Geophys. Res. Lett., 34, L11105, doi:10.1029/2007GL029881.

Sternovsky, Z., S. Robertson, A. Sickafoose, J. Colwell, and M. Horányi (2002), Contact charging of lunar and Martian dust simulants, J. Geophys. Res., 107(E11), 5105, doi:10.1029/2002JE001897.

Stolzenburg, M., T. Marshall, and W. Rust (2001), Serial soundings of electric field through a mesoscale convective system, J. Geophys. Res., 106, 12,371-12,380, doi:10.1029/2001JD900074

Takahashi, Y., J. Yoshida, Y. Yair, T. Imamura, and M. Nakamura (2008), Lightning detection by LAC onboard the Japanese Venus climate orbiter, Planet-C, Space Sci. Rev., 137, 317-334, doi:10.1007/s11214-008-9400-x.

Tokano, T., G. J. Molina-Cuberos, H. Lammer, and W. Stumptner (2001), Modelling of thunderclouds and lightning generation on Titan, Planet. Space Sci., 49, 539-560, doi:10.1016/S0032-0633(00)00170-7.

Treumann, R. A., Z. Klos, and M. Parrot (2008), Physics of electric discharges in atmospheric gases: An informal introduction, Space Sci. Rev., 137, 1-4, doi:10.1007/s11214-008-9355-y.

Whitten, R. C., W. J. Borucki, and S. Tripathi (2007), Predictions of the electrical conductivity and charging of the aerosols in Titan's nighttime atmosphere, J. Geophys. Res., 112, E04001, doi:10.1029/2006JE002788. 
Williams, E., M. Valente, E. Gerken, and R. Golka (2006), Calibrated radiance measurements with an air-filled glow discharge tube: Application to sprites in the mesosphere, in Sprites, Elves and Intense Lightning Discharges, edited by M. Fullekrug et al., pp. 237-247, Springer, Dordrecht, Netherlands.

Williams, M. A., E. P. Krider, and D. M. Hunten (1983), Planetary lightning: Earth, Jupiter and Venus, Rev. Geophys., 21, 892-902, doi:10.1029/ RG021i004p00892.

Wilson, C. T. R. (1925), The electric field of a thundercloud and some of its effects, Proc. Phys. Soc. London, 37, 32D-37D.

Yair, Y., Z. Levin, and S. Tzivion (1995), Lightning generation in a Jovian thundercloud: Results from an axisymmetric numerical cloud model, Icarus, 114, 278-299, doi:10.1006/icar.1995.1062.

Yair, Y., Z. Levin, and S. Tzivion (1998), Model interpretation of Jovian lightning activity and Galileo's probe results, J. Geophys. Res., 103, 14,157-14,166, doi:10.1029/98JD00310.

Yair, Y., C. Price, Z. Levin, J. Joseph, P. Israelevitch, A. Devir, M. Moalem, B. Ziv, and M. Asfur (2003), Sprite observations from the space shuttle during the Mediterranean Israeli Dust Experiment (MEIDEX), J. Atmos. Sol. Terr. Phys., 65, 635-642, doi:10.1016/S1364-6826(02)00332-2.

Yair, Y., P. Israelevich, A. D. Devir, M. Moalem, C. Price, J. H. Joseph, Z. Levin, B. Ziv, A. Sternlieb, and A. Teller (2004), New observations of sprites from the space shuttle, J. Geophys. Res., 109, D15201, doi:10.1029/2003JD004497.

Yair, Y., G. Fischer, F. Simoes, N. Renno, and P. Zarka (2008), Updated review of planetary atmospheric electricity, Space Sci. Rev., 137, 29-49, doi:10.1007/s11214-008-9349-9.

Yang, H., V. Pasko, and Y. Yair (2006), Three-dimensional finite-difference time-domain modeling of the Schumann resonance parameters on Titan, Venus and Mars, Radio Sci., 41, RS2S03, doi:10.1029/2005RS003431.

U. Ebert, Centrum Wiskunde and Informatica, P.O. Box 94079, NL-1090 GB Amsterdam, Netherlands.

Y. Goto, Department of Electrical Engineering, Tohoku Gakuin University, Tagajo, Miyagi 985-8537, Japan.

Y. Takahashi, Department of Geophysics, Tohoku University, Sendai, Miyagi 980-8578, Japan.

Y. Yair, Department of Life and Natural Sciences, Open University of Israel, 108 Ravutski Street, Ra'anana 43107, Israel.

R. Yaniv, Department of Geophysics and Planetary Sciences, Tel-Aviv University, Haim Levanon Road, Ramat-Aviv, Tel-Aviv 69978, Israel. 